\title{
CEDES E V SEB EM TEMPOS DE PÁTRIA EDUCADORA
}

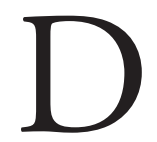

e 15 a 17 de junho de 2015, foi realizada na Universidade Estadual de Campinas (Unicamp) mais uma edição do Seminário de Educação Brasileira, o V SEB. Desde o I SEB e o primeiro número da Revista Educação e Sociedade (E\&S), os debates ali desenvolvidos estiveram focados sobre o cenário político educacional brasileiro.

O tema do I SEB - Análise de currículo e conteúdo programático dos Cursos de Pedagogia com vistas a propostas alternativas de reformulação - visou articular as relaçóes entre as discussóes políticas e a produção da investigação educacional. A temática, resultante de uma pesquisa de âmbito nacional, desenvolvida no então Departamento de Sociologia da Educação da Faculdade de Educação (FE/Unicamp), foi amplamente debatida no primeiro número da Revista E\&S de setembro de 1978, cujo tema, O educador precisa ser educado, "[...] tentava circunscrever a estrutura e a situação da pedagogia na educação brasileira [...] e sua interação com o contexto brasileiro [...]".

A importância histórica nacional da Revista E\&S, "portadora da produção e reflexão-ação na educação”, e dos Seminários de Educação Brasileira, ambos parte integrante da história da educação brasileira, levaram à criação do Centro de Estudos Educação e Sociedade (Cedes), em 5 de março de 1979, conforme ficou registrado no Editorial do n.2 de janeiro de 1979.

Distanciando-se do imperialismo político-cultural que tentava "congelar as instituições de ensino e pesquisa no conjunto da nação", o Cedes foi institucionalizado desafiando "o isolamento conduzido pelo Estado, ampliando o campo da ação dos educadores". A partir daquele momento, a Revista E\&S, no Cedes, "[...] passa a ser um espaço de integração e de associação de todos os educadores que queiram retomar a educação na perspectiva de suas relaçóes com a sociedade $[\ldots]$ "... 
No Editorial da revista n.3, de maio 1979, o Seminário de Educação Brasileira é caracterizado como:

[...] atividade marcante do CEDES [...] para discutir seus problemas, aprofundar temas de relevância da atualidade educacional brasileira, propor soluçóes e manter o intercâmbio necessário para prosseguir na luta comum por melhores condiçóes de trabalho, de pesquisa, de ensino e de aprendizagem continuada.

Por decisão coletiva, o II SEB, previsto para fevereiro de 1980, com o tema Política educacional brasileira, ampliou seu espaço articulando-se com outras entidades, como Anped e Ande, para a realização conjunta das Conferências Brasileiras de Educação (CBEs), das quais a primeira teve como tema a Política Educacional. Seguiu-se uma série de seis conferências, mostrando a força política do debate social promovido pelas mais representativas entidades democráticas de educadores do país.

Todavia, após longo período sem eventos desta natureza e percebendo a necessidade do restabelecimento de um espaço coletivo de discussão das urgentes questóes referentes à conjuntura educacional nacional, o Cedes retomou a série dos SEBs em 2006, chegando agora à sua quinta edição.

O V SEB buscou analisar a conjuntura atual da educação nacional a partir da temática Mudanças atuais na sociedade brasileira e o Sistema Nacional de Educação: qualidade da educação pública como direito humano, mantendo a tradição focada no estudo das políticas públicas da educação no contexto da (re)significação da relação entre educação e sociedade.

O tema desta versão dos SEBs, conforme anunciado no Editorial da revista n. 129, discutiu as mudanças conjunturais e seus impactos no sistema nacional de educação, em processo de implementação. Visando à defesa da educação de qualidade, considerada como direito humano, foram analisadas as proposições antagônicas de políticas educacionais e sua concertação, transliteradas no Plano Nacional de Educação (PNE).

No desenrolar do V SEB, observou-se, de um lado, que os debates e a produção do conhecimento no campo das políticas educacionais no mundo do trabalho em suas dimensóes sócio-espaciais e econômicas têm privilegiado o urbano em detrimento do rural; de outro lado, as novas relaçóes público/privado têm incidido fortemente sobre o direito à educação pública de qualidade referenciada, substituído pelo denominado "direito à aprendizagem”, concepção esta sustentada em categorias de aprendizagem pretensamente mensuráveis. Nessa direção, considerando a gravidade das circunstâncias que envolvem hoje o quadro político da educação brasileira, a plenária de educadores participantes do V SEB elaborou 
três Moçóes (transcritas na íntegra no final deste editorial), dirigidas ao Governo Federal, ao Ministro da Educação, à Secretaria de Articulação com os Sistemas de Ensino (Sase), à Fundação Coordenação de Aperfeiçoamento de Pessoal de Nível Superior (Capes), ao Fórum Nacional da Educação (FNE), bem como ao Instituto Ayrton Senna.

As preocupaçóes com a atual conjuntura educacional nos levam igualmente a realizar consideraçóes críticas sobre o documento Pátria Educadora: a qualificação do ensino básico como obra de construção nacional, divulgado, em versão preliminar, no dia 22 de abril de 2015, pela Secretaria de Assuntos Estratégicos da Presidência da República. Desde então, este documento tem se constituído objeto de análises e importantes críticas por parte de diferentes entidades acadêmicas e sindicais, sociedades científicas, grupos de pesquisa e faculdades de educação pelo seu conteúdo político e forma de elaboração.

Um dos principais aspectos das críticas ao documento diz respeito à desconsideração, em seu conteúdo, tanto do PNE quanto das análises e proposiçóes das Conferências Nacionais de Educação (Conae), conforme já foi destacado na 26a Nota Pública do FNE. O documento, pautado pela lógica da meritocracia empresarial e dos paradigmas da qualidade total, além de não se referenciar no PNE, envolve retrocessos políticos e conceituais, já exaustivamente contestados e refutados pelos movimentos educacionais de resistência nos anos 1990. A premiação de escolas, diretores e professores, por exemplo, desilude profissionais não afeitos ao cumprimento das metas previstas no documento, reforçando, assim, uma ideologia ancorada no 'darwinismo social' e contrária aos avanços político-conceituais alcançados pelas conferências de educação em prol de uma educação de qualidade socialmente referenciada.

Em nome da meritocracia, o documento Pátria Educadora surpreende, ainda, pelo seu caráter segregador ao propor medidas intervencionistas e genéricas para premiar e punir escolas. A proposta da criaçáo das Escolas Anísio Teixeira, além de desonrar o nome de um dos educadores mais comprometidos com a escola pública e a democratização do ensino na história do país, preconiza a formação de "ilhas de excelência" no sistema federal de ensino, destinadas, mediante processos seletivos, ao acolhimento dos "alunos com maior potencial”. Ademais, reforça estigmas de estratos empobrecidos da população ao propor que é necessário permitir "[...] à massa de alunos, vindos do meio pobre, superar as barreiras pré-cognitivas que os impedem de aceder às capacitaçóes analíticas. Será obra de libertação". (BRASIL, 2015, p. 06, disponível em http://www.mec.gov.br) Assim, assumem relevância, no documento, as propaladas competências socioemocionais: "[...] trata-se de trabalhar no terreno de capacitaçóes pré-cognitivas que faltam a crianças saídas da pobreza mais comumente do que faltam aos filhos da classe média [...]". Noçóes estereotipadas das camadas empobrecidas e o papel da escola 
como redentora no processo de gestão da pobreza são veiculados pelo documento ao ressaltar que

[...] nas periferias e nos bairros pobres de nossas cidades, mais da metade das famílias costuma ser conduzida por mãe sozinha, casada ou solteira. Revezam-se os homens como companheiros instáveis. Esta mãe, pobre e geralmente negra ou mestiça, luta para zelar pelos filhos e para manter ao mesmo tempo emprego ou biscate [...]. (BRASIL, 2015)

Além disso, o documento faz duas proposiçóes que preocupam. A primeira refere-se à possibilidade de retorno ao enfoque de formação por competências ao afirmar, fazendo a crítica do enciclopedismo, que "[...] o aprofundamento seletivo é o terreno para o domínio das capacitaçóes analíticas [...]" e que "[...] o currículo nacional deve ser, portanto, organizado como sequência de capacitaçóes, adquiridas e exercitadas em campos variáveis [...]”. A segunda póe em questão o trabalho docente ao afirmar que "[...] o currículo [...] deve também comportar sequências especiais, para os alunos que enfrentem maior dificuldade ou que demonstrem maior potencial [...]", as quais “[...] precisam ser encarnadas em rico repertório de protocolos disponibilizados aos professores [...]”. Tais protocolos, segundo o texto, "[...] darão exemplos práticos e pormenorizados de como liderar cada aula em cada disciplina [...]".

O documento Pátria Educadora apresenta inconsistências também no concernente a aspectos estruturais da educação brasileira como o enfrentamento às desigualdades regionais relacionadas ao financiamento educacional. A minuta propóe a formação de órgãos colegiados e transfederativos, visando a intervenção nos Estados e Municípios para coordenar açóes destinadas a

[...] assegurar patamar nacional mínimo de desempenho e qualidade. Tais órgãos tomarão iniciativas de apoio, de gestão e de direcionamento de recursos humanos e financeiros. Poderão, quando necessário, afastar e substituir diretores de escola [...].

Contudo, a desigualdade fiscal dos entes federados no provimento dos serviços educacionais tem indicado a urgente e necessária construção de outro modelo de pacto federativo mediante a elevação do padrão de qualidade. Vale lembrar que, em um país com dimensóes continentais como o Brasil, a estrutura federativa guarda complexidades e distorçôes. Assim, as assimetrias presentes nas regiōes e nos Estados da federação são emblemáticas das fragilidades estruturais do sistema federativo brasileiro e das dificuldades da participação da União na execução de açóes redistributivas. 
Para a minimização dos efeitos adversos de tais assimetrias é premente a ampliação de recursos de financiamentos para a educação. Um mecanismo tangível, e que se constitui em um dos desafios para o tempo presente, diz respeito à regulamentação da aplicação dos recursos oriundos dos royalties do Petróleo, aspecto que pode impactar positivamente na qualidade da educação e, por consequência, na valorização dos profissionais da educação. Contudo, vale destacar que tal mecanismo é importante, mas, não suficiente para a garantia da efetivação da meta 20 do Plano Nacional de Educação, a qual determina a aplicação de $10 \%$ do PIB para a educação.

Enfim, são múltiplas as inconsistências, ambiguidades e contradições presentes no documento Pátria Educadora. Embora a Secretaria de Assuntos Estratégicos (SAE) tenha submetido o documento, em sua versão preliminar, ao debate de diferentes instâncias da sociedade civil, o distanciamento da SAE das entidades educacionais na elaboração do documento é emblemático das divergências estruturais e pontuais entre o conteúdo do documento e o ideário dos documentos das Conferências Nacionais de Educação. Causa-nos também perplexidade, o fato desse documento ser oriundo de uma Secretaria de Governo sem a participação direta do Ministério da Educaçáo, o qual figura apenas como executor da proposta. Maior apreensão surge com a notícia, fornecida pelo próprio Ministro Mangabeira Unger, de que outros documentos estariam sendo gestados nos mesmos moldes.

Frente a tais desmandos antidemocráticos e incongruências na construção dos Planos Educacionais Municipais e Estaduais em todo o país, aos avanços dos processos de privatização protagonizados pelos "reformadores empresariais" em parceria com a administração pública de diferentes esferas da federação, sob o respaldo das ambiguidades permissivas do texto do Plano Nacional da Educação aprovado pelo Congresso Nacional, o Cedes propóe reforçar, em ação conjunta com as outras entidades representativas do campo educacional, a pauta de luta que nos conduziu na elaboraçáo do documento da Conae, contra a meritocracia, responsabilização e privatização, em defesa da escola pública de qualidade social para todos, hoje expressa no FNE.

Cumprindo a data prevista no PNE, foi publicada a Resolução CNE/ CP 2/2015 - no Diário Oficial da República Federativa do Brasil, 2 de julho de 2015, seção 1, p. 8-12 -, que define as Diretrizes Curriculares Nacionais para a formação inicial em nível superior (cursos de licenciatura, cursos de formação pedagógica para graduação e cursos de segunda licenciatura) e para a formação continuada. Esta temática abre a revista em artigo de autoria do Conselheiro Relator Luiz Fernandes Dourado. 


\section{MOÇÃO DO VSEB \\ CEDES CONTRA A MENSURAÇÃO DE COMPETÊNCIAS SOCIOEMOCIONAIS COMO POLÍTICA PÚBLICA}

Nós, educadores, pesquisadores, estudantes, professores de rede pública e privada de ensino, psicólogos, pedagogos e outros profissionais, reunidos durante o V Seminário de Educação Brasileira, SEB, na UNICAMP, Campinas, SP, manifestamos nossas preocupações e posicionamo-nos contrários a qualquer forma de mensuração de competências socioemocionais, tal como na proposta denominada Social and Emotional Non-cognitive Nationwide Assessment, SENNA, do Instituto Ayrton Senna, em parceria com a Secretaria Estadual de Educação do Rio de Janeiro (SEEDUC) e a Organização para a Cooperação e Desenvolvimento Econômico (OCDE).

Diante do exposto, apresentamos, neste manifesto, as razóes de nosso posicionamento:

1. O instrumento se ancora em uma concepção naturalizante da personalidade humana ao se basear na antiga e já criticada psicologia de traços que assume cinco fatores básicos como características universais do humano.

2. O instrumento separa os aspectos afetivos dos aspectos cognitivos, indo na contramão das teorizaçóes e pesquisas em diversos campos do conhecimento, desde a Psicologia e a Pedagogia, até as Ciências Sociais e a Neurologia.

3. O instrumento de mensuração desconsidera as experiências e os saberes dos professores no chão da escola e não leva em conta as condiçóes desta como instituição social para acolher alunos e alunas, com sua cultura, suas experiências e dificuldades de vida.

4. O pensamento métrico / psicométrico, que pressupõe um padrão único e estimula a homogeneização, desconsidera a diversidade e as condições de desigualdade social, dando margem à estigmatização e produzindo a patologização da diferença.

5. A Psicologia, durante os últimos 30 anos, tem feito grande esforço para produzir novas concepçóes que lhe permitam um diálogo e uma participação transformadora com e na educação sem ditar as finalidades desta última. Não é consenso, no campo da Psicologia, a ideia de medir competências psicológicas e comportamentais como forma de fazer avançar o processo de ensino-aprendizagem. 
Pelas razóes aqui elencadas e tendo em vista uma educação de qualidade e o fim da desigualdade social em nosso país, repudiamos essa proposta de aplicação dos testes em larga escala para mensuração de competências sócio emocionais e sua utilização como instrumento de apoio a políticas públicas. Entendemos que o MEC deve abrir a discussão sobre o assunto, colocando sobre a mesa, de forma transparente, a proposta do Instituto Ayrton Senna de criar uma ferramenta única e unilateral de medida de competências sócio emocionais.

\section{MOÇÃO DO V SEB CEDES À SASE EM PARCERIA COM FNE}

Nós, associados do CEDES - Centro de Estudos Educação e Sociedade, pesquisadores e educadores, presentes no V SEB - SEMINÁRIO DE EDUCAÇÃO BRASILEIRA, realizado no Centro de Convençóes da UNICAMP, de 15 a 17 de junho de 2015 dirigimo-nos respeitosamente ao Sr. Arnóbio Marques, Secretário da SASE - Secretaria de Articulação com os Sistemas de Ensino, a fim de solicitar estudo complementar ao realizado de caráter quantitativo sobre os Planos de Educação Estaduais e Municipais que verse sobre os processos adotados na formulação e na aprovação dos referidos Planos, abordando desde a elaboração do diagnóstico até o processo de participação e votação nas casas legislativas.

Nossa solicitação tem base na constatação - tanto pelas notícias veiculadas nos diversos meios de comunicação como pela participação de muitos de nós, associados do CEDES, enquanto representantes de entidades ou delegados de conferências nos Fóruns Municipais e Estaduais - acerca dos processos antidemocráticos, gerencialistas e alienantes que marcaram diversas formulaçóes de Planos Municipais e Estaduais de Educação; situação essa, já por nós denunciada junto ao Fórum Nacional de Educação.

Consideramos os percalços de uma mobilização que vise reverter estes cenários, daí porque buscar outras formas de não só conhecer com propriedade as realidades que marcaram a construção dos Planos, como também reunir material para instrumentalizar-nos frente às discussóes que serão responsáveis por delinear as açóes educacionais que marcarâo a próxima década.

O estudo quantitativo já existente aporta dados importantes para avaliação e compreensão do panorama que se forma, todavia ponderamos ser esse insuficiente para qualificar os inúmeros desafios que marcaram e continuarão marcando a construção de Planos de Educação condizentes com as realidades locais e regionais. 
Assim, nós associados do CEDES, temos a convicção de que tal perspectiva será lograda com uma abordagem qualitativa dos processos, ação que pode ser realizada com primazia por meio desta M.R. Secretaria em parceria com o FNE.

\section{MOÇÃO DO VSEB CEDES AO FNE}

Nós, associados do CEDES - Centro de Estudos Educação e Sociedade, pesquisadores e educadores, presentes no V SEB - SEMINÁRIO DE EDUCAÇÃO BRASILEIRA, realizado no Centro de Convençóes da UNICAMP, de 15 a 17 de junho de 2015 dirigimo-nos respeitosamente dirigimo-nos respeitosamente ao Fórum Nacional de Educação, a fim de solicitar:

1. que acompanhe a mobilização/criação/fortalecimento dos Fóruns Municipais - FME e Estaduais de Educação - FEE, instrumentados pela criação de redes, de modo a garantir o acompanhamento do cumprimento de metas fundamentais para a educação nacional, principalmente aquelas que dizem respeito: à expansão da educação pública em todos os seus níveis; à definição de políticas de formação e de valorização dos profissionais da educação; e, à regulação do setor privado, proposição presente em raras estratégias do PNE;

2. que caracterize a próxima década da Educação em nosso país pela participação popular, marca de nossa Carta Magna Cidadã e do Brasil que, desde 1988, estamos construindo;

3. que se institua no interior do FNE assim como em cada Fórum Estadual e Municipal um canal de comunicação entre a população e o poder público, de forma a coordenar o monitoramento do cumprimento das metas dos respectivos Planos de Educação;

4. que o FNE se estabeleça como referência nacional das entidades representativas de todos os setores e segmentos da sociedade, comprometendo-se com a discussão ampla e democrática das políticas educativas em construção pelos entes federados, com o acompanhamento abalizado nas açóes legislativas do Congresso Nacional e a mobilizaçáo permanente dos educadores para a vigilância firme e positiva dos FMEs no processo de cumprimento dos Planos estaduais e municipais.

Assim, nós associados do CEDES, pesquisadores e educadores presentes no VSEB temos a convicção de que tais solicitaçóes podem ser logradas com primazia por esse Fórum. 


\section{Nota}

Durante muitos anos Patrizia Piozzi foi nossa companheira de trabalho no Conselho Editorial da Revista Educação \& Sociedade. Seus conhecimentos, seu decidido engajamento na luta por uma educação mais democrática e de melhor qualidade para todos e, ainda, sua contagiante alegria em todos os momentos de trabalho e convivialidade são tijolo e cimento disso que o Cedes e a Educaçáo \& Sociedade puderam construir ao longo dessas últimas décadas.

DOI: http://dx.doi.org/10.1590/ES0101-73302015V36N131 